\title{
Are Fluoroscopic Caudal Epidural Steroid Injections Effective for Managing Chronic Low Back Pain?
}

\author{
Daniel Southern, MD, Gregory E. Lutz, MD, Grant Cooper, MD, and Lisha Barre, MD
}

\begin{abstract}
Objective: This study sought to determine the efficacy of fluoroscopic caudal epidural steroid injections as a conservative treatment in patients with presumably chronic lumbar discogenic pain.

Summary of Background Data: Epidural steroid injections have been used in the treatment of lumbar radicular pain with success. However, despite their widespread use, there are few, if any, reports of the efficacy of Epidural steroid injections in patients with predominantly axial lumbar pain. Prior studies have been limited by the use of nonfluoroscopically guided injections and failing to apply a specific injection approach (i.e.
\end{abstract}

Chronic low back pain is the number one cause of disability in people under age of 45 and the third most common cause of disability for those over 45(1). Traditional conservative medical treatments for patients with chronic low back pain have included trials of oral medication, exercise therapies, manual therapies, back school, and lifestyle modifications. In addition, first advocated in 1952 by Robecchi and Capra (2), lumbar epidural steroid injections have also become a widely utilized conservative therapeutic modality in the treatment of patients with chronic low back pain.

Steroid injections may be delivered to the lumbar epidural space via a caudal, interlaminar, or transforaminal route. More than 40 papers have reported on clinicians' experiences with epidural steroid injections(3). Reported success rates range from $20-100 \%$, with an average of $67 \%(4)$ Three major limitations, however, exist in most of these reports. First, Previous investigations have evalu-

From Hospital for Spinal Surgery, Department of Physiatry, New York, NY. Address Correspondence: Gregory E. Lutz, MD, 535 East $70^{\text {th }}$ St, New York, NY 10021. E-mail: glutz@hss.edu

There was no external funding in preparation of this manuscript. transforaminal, interlaminar, or caudal) to a specific patient population.

Methods: Ninety-seven patients with chronic axial low back pain and Magnetic Resonance Imaging evidence of disc pathology without stenosis were selected from chart review. All patients received at least one fluoroscopically guided caudal epidural injection with $12 \mathrm{mg}$ of betamethasone and $8 \mathrm{cc}$ of $0.5 \%$ lidocaine. Collected follow-up information included Roland-Morris Disability, Visual Numeric Pain Scale, and patient satisfaction scores.

Results: Only nineteen patients (23\%) were determined to have a successful longterm (>1 year) outcome and 65 (77\%) were deemed failures. Average follow-up was $28.6 \pm 15.6$ months. Successes were found to differ significantly from failures in pre-injection pain scores and patient satisfaction. Overall patient satisfaction was $45 \%$.

Conclusion: At greater than two year follow-up, the efficacy of fluoroscopically guided caudal epidural steroid injections in patients with chronic lumbar discogenic pain is poor. Patient satisfaction exceeds the reported rate of efficacy. Patients responding to injection have significantly lower pre-injection pain scores.

Key Words: low back pain, epidural steroid injections, caudal, inter laminar, transforaminal ated a mixture of the three steroid delivery approaches (caudal, interlaminar, and transforaminal), each of which may have different efficacy rates (5). Second, Previous investigations have evaluated mixed patient populations (i.e., disc herniations, spinal stenosis, spondylolisthesis, postsurgical,) with mixed symptomatology (primarily axial low back pain, primarily radicular pain), each of which may respond differently to epidural steroid injections. Finally, most previous studies failed to use fluoroscopic guidance with preinjection contrast to document the epidurogram and proper flow to the target tissue. Reports have shown that even in experienced hands, epidural injectate may be misplaced in up to $30 \%$ of cases (6).

Failing to stratify patient sub-populations according to their specific clinical characteristics and underlying pathology, and failing to apply a specific treatment (caudal vs. transforaminal, vs. interlaminar route of injection) makes it difficult to assess the efficacy of epidural steroid injections in the treatment of back pain. In 1998, Lutz et al (7) studied the efficacy of fluoroscopically guided transforaminal epidural steroid injections as a treatment for patients with a history and physical examination consistent with lumbar radicu- lopathy and magnetic resonance imaging results documenting a herniated nucleus pulposus. Lutz et al (7) found that in this specific patient population, fluoroscopically guided transforaminal epidural steroid injection had a $75.4 \%$ long-term (average follow-up of 80 weeks, range of 28 144 weeks) success rate. This study highlights the importance of evaluating a specific treatment for a specific diagnosis.

While the natural history of low back pain may be favorable in some, others can be left with chronic, constant, disabling low back pain. Many of these patients do not respond to oral medications and physical therapy. The next treatment option for these patients, typically, is epidural steroid injection. Since the perceived target area of pain and inflammation in this patient subset is the ventral, central epidural space, a caudal injection providing nonspecific ventral epidural flow would possibly be the best choice of epidural steroid injection in this population. To date, no study has specifically investigated the efficacy of fluoroscopic caudal epidural steroid injection as a treatment for patients with chronic lumbar discogenic back pain. The purpose of this study, therefore, was to retrospectively evaluate the efficacy of fluoroscopical- 
ly guided caudal epidural steroid injection in this specific subset of patients.

\section{Methods}

Patients who were seen in an academic outpatient physiatric interventional spine practice between 1996 and 2002 and who had received at least one fluoroscopically guided caudal epidural steroid injection were considered for the study. Inclusion criteria included

1. predominately axial low back pain of more than three months duration.

2. failure of conservative treatment (i.e NSAIDs, physical therapy).

3. clinical presentation and magnetic resonance imaging findings consistent with central lumbar disc protrusion and/or degeneration at L4-L5 or L5-S1. Exclusion criteria included previous spinal surgery, spondylolysis/spondylolisthesis, fractures and spinal stenosis.

All patients who qualified for the study were mailed a Roland-Morris Disability Questionnaire, a Visual Numeric Pain Scale (VNS) and a North American Spine Society (NASS) patient satisfaction questionnaire. Included were questions about interventions subsequent to their caudal epidural steroid injection. Patients who had not returned the questionnaires by mail within three weeks were telephoned and asked the questions over the phone by an independent observer.

Patients who reported having a subsequent discography and/or surgery after their injection were deemed procedure failures. Successes were those patients who scored 1-2 on the NASS patient satisfaction (Table 1), had a greater than $50 \%$ reduction in VNS and a greater than 2 point change in the Roland-Morris scale (Table 2). Patients failing to meet these criteria were included with those having subsequent surgery as procedure failures.

All patients received a caudal epidural injection under fluoroscopic guidance. The patients were placed on a fluoroscopy table in the prone position. After the usual sterile prep, drape and local anesthesia, a 22 gauge spinal needle was advanced through the sacrococcygeal ligament in to the sacral epidural space in a midline position. Both antero-posterior and lateral fluoroscopic images confirmed proper needle placement. Omnipaque 180 contrast was then injected to document epi-

\section{Table 1. Patient Satisfaction*}

\begin{tabular}{|c|l|}
\hline Score & \\
\hline 1 & Epidural steroids met my expectations \\
\hline 2 & $\begin{array}{l}\text { I improved less than I had hoped, but I would undergo the same procedure again } \\
\text { for the same result }\end{array}$ \\
\hline 3 & $\begin{array}{l}\text { Epidural steroids helped, but I would not undergo the same procedure for the } \\
\text { same result. }\end{array}$ \\
\hline 4 & I am the same or worse than before epidural steroids. \\
\hline
\end{tabular}

*North American Spine Society

Table 2. Outcome criteria ${ }^{*}$
\begin{tabular}{|c|c|c|c|c|}
\hline & $\begin{array}{c}\text { Post-ESI } \\
\text { Procedure }\end{array}$ & $\begin{array}{c}\text { Patient } \\
\text { Satisfaction* }\end{array}$ & VNS & $\begin{array}{c}\text { Roland- } \\
\text { Morris }\end{array}$ \\
\hline Successes & None & $1-2$ & $>50 \%$ & $>=2$ pt. \\
\hline Failures & $\begin{array}{c}\text { None or } \\
\text { Yes }\end{array}$ & $3-4$ & $<=50 \%$ & $<2$ pt. \\
\hline
\end{tabular}

ESI = Epidural Steroid Injection

VNS = Visual Numeric Analog Pain Scale

*North American Spine Society
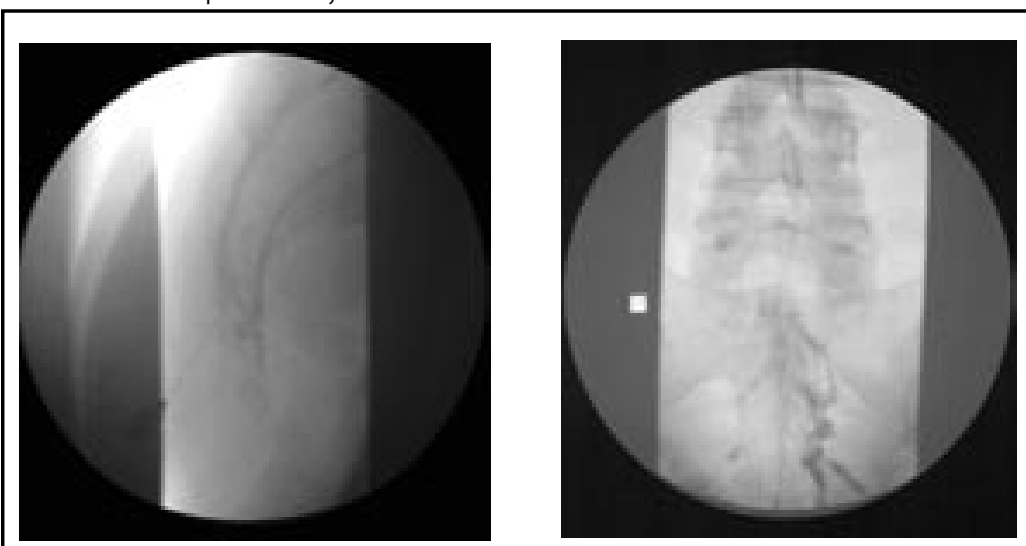

Fig. 1 fluoroscopic views, before and after contrast, of a caudal epidural

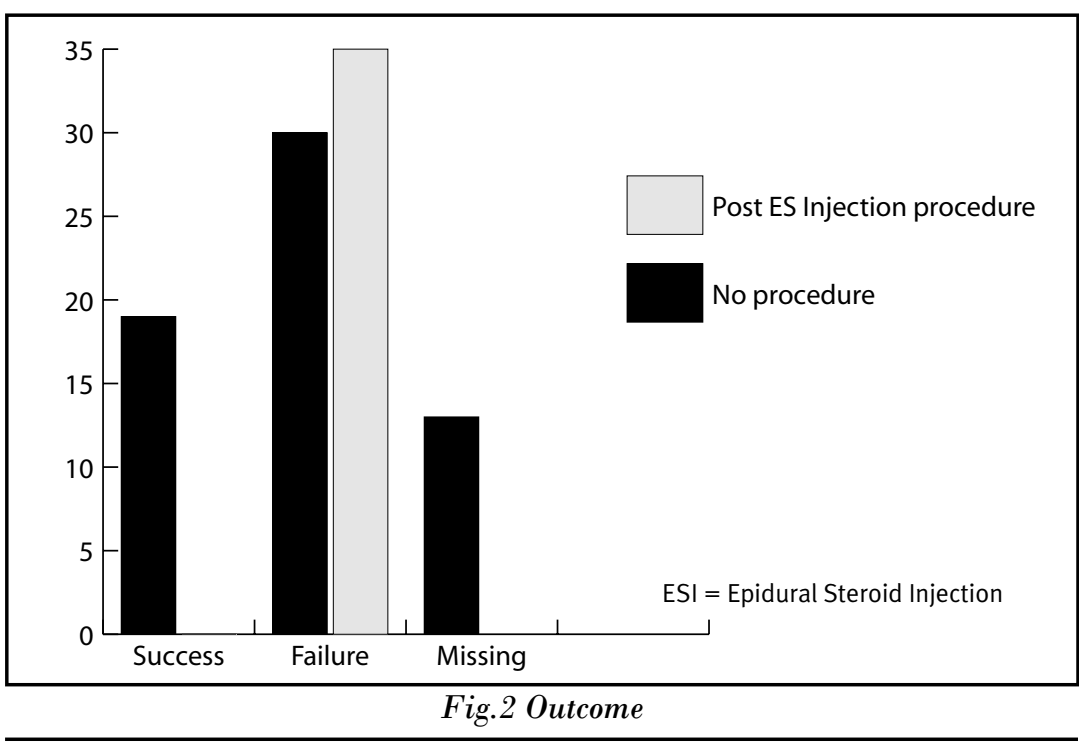


dural flow to the target level (Fig 1). If the flow was intravascular or unilateral, the needle was repositioned to achieve proper flow. Once proper epidural spread was documented, $12 \mathrm{mg}$ of Betamethasone and $8 \mathrm{cc}$ of $0.5 \%$ lidocaine (Xylocaine ${ }^{\circledR}$, preservative free) were injected. The needle was then removed and the patient was observed for any adverse reaction. A single investigator (GEL) administered all injections. The patients were re-evaluated at one week. If they received significant pain relief $(>80 \%)$, no further injections were given. If they received partial pain relief, a repeat injection was given at 2 weeks intervals. If they received no relief, no further epidural injections were given.

Those patients that responded favorably were then placed back into a spine rehabilitation program for 4 to 6 weeks to maximize their functional gains. Those patients who did not respond or responded for only a short period were then offered discography for pre-surgical planning.

Visual numeric pain scale scores (VNS) were obtained at the first clinical presentation prior to injection. Patients filled out VNS scores on the follow-up questionnaire and were asked to recall the worst level of pain prior to injections and the worst level of pain in the week prior to follow-up. Where these recalled scores differed from those obtained at baseline, the baseline scores were used. For patients classified as failures due to subsequent surgery, follow-up VNS scores were considered to be unchanged from baseline and the baseline score was recorded.

Charts were also reviewed for magnetic resonance imaging findings, diagnosis, age at onset of symptoms, duration of symptoms prior to injection, number of injections, subsequent procedures (including discography, intradiscal-electrothermal therapy (IDET), or spinal fusion), associated spondylolisthesis, and type of insurance. Non-parametric data were analyzed using the Mann-Whitney and Fisher's Exact test and parametric data were analyzed using the independent samples T-test. Significance was set at $\mathrm{p}<0.05$ with $95 \%$ confidence intervals. Data was analyzed using SPSS Version 9.0 software.

\section{RESULTS}

Four thousand seven hundred and fifty-six charts were reviewed to identify 98 subjects who met the inclusion criteria. One patient, who had no address list-

Table 3. Outcome by Diagnosis*

\begin{tabular}{|c|c|c|c|}
\hline Diagnosis & Successes & Failures & Total \\
\hline Herniated Disc & 14 & 41 & 55 \\
\hline Non-Herniated Degenerative Disc & 5 & 24 & 29 \\
\hline Total & 19 & 65 & 84 \\
\hline
\end{tabular}

*Chi-Square $p=0.39$

Table 4. Outcome groups by variables

\begin{tabular}{|c|c|c|c|c|}
\hline & Outcome & $\mathbf{N}$ & Mean & $\begin{array}{l}\text { Standard } \\
\text { Deviation }\end{array}$ \\
\hline \multirow{2}{*}{ Age in years* } & $\mathrm{S}$ & 19 & 40.4202 & 12.0945 \\
\hline & $\mathrm{F}$ & 65 & 41.5301 & 11.4102 \\
\hline \multirow{2}{*}{ Age at onset* } & $\mathrm{S}$ & 19 & 36.9014 & 11.7921 \\
\hline & $\mathrm{F}$ & 65 & 37.3220 & 11.6500 \\
\hline \multirow{2}{*}{ Follow-up duration in months* } & $\mathrm{S}$ & 19 & 24.8804 & 14.9704 \\
\hline & $\mathrm{F}$ & 65 & 29.6929 & 15.7452 \\
\hline \multirow{2}{*}{ Duration of Symptoms in months ${ }^{\wedge}$} & S & 19 & 16.8070 & 28.1780 \\
\hline & $\mathrm{F}$ & 65 & 20.6518 & 26.7487 \\
\hline \multirow{2}{*}{ Number of Injection^^} & $\mathrm{S}$ & 19 & 1.5263 & 0.5130 \\
\hline & $\mathrm{F}$ & 65 & 1.4769 & 0.6400 \\
\hline \multirow{2}{*}{ VNS Pre-Injection** } & $\mathrm{S}$ & 19 & 8.53 & 1.17 \\
\hline & $\mathrm{F}$ & 64 & 9.09 & 1.15 \\
\hline \multirow{2}{*}{ 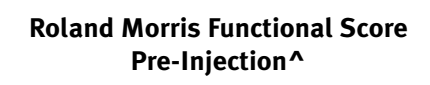 } & $\mathrm{S}$ & 19 & 11.32 & 4.68 \\
\hline & $\mathrm{F}$ & 53 & 11.96 & 6.49 \\
\hline
\end{tabular}

${ }^{\star} p>0.05$ (Independent Sample t-test) ${ }^{\star \star} p<0.05$ (Mann-Whitney test for ordered data) $\wedge p>0.05$ (Mann-Whitney)

ed and no valid phone number, could not be included. Ninety-seven (97) patients, 38 men and 59 women, with a mean age of 42.2 years (range 16 to 70 ), were included in the study. Average pre-injection duration of symptoms was 21.5 months (range 3 to 175 ).

Initial follow-up questionnaires were answered by 71 patients. Twentysix patients could not be reached. For 13 of these patients, follow-up data was obtained from the chart indicating that they had failed the injection and went on to discography. These were included in the study as procedure failures. Followup data was obtained on a total of 84 patients $(87 \%)$. Thirteen were lost to follow-up (13\%). Average length of followup was $28.6 \pm 15.6$ months with a minimum of 3.0 months and a maximum of 61.2 months.

Based on the criteria listed in Table 2, 19 of 84 patients $(23 \%)$ were classified as successes and 65 as failures (77\%). Thirty-five $(35 / 84$ or $40 \%)$ patients had no short or long term pain relief. Thirty of these patients (30/35) underwent discography for pre-surgical planning and all 30 were found to have concordant low back pain. The remaining failures $(30 / 84$ or $37 \%$ ) had either partial pain relief that was insufficient to meet the success criteria, or they had no pain relief but did not want to proceed with other more aggressive treatment (Fig 2).

Sixty-four patients were diagnosed with herniations of the lumbosacral discs; 48 were central and 16 paracentral. Degenerative disc without herniation was the diagnosis in 33 patients. The suspected disc level was L5-S1 in 48 patients, L4-L5 in 33 patients, and L3-L4 in 2 patients. There were no significant differences in outcome between these diagnostic groups (Table 3 ).

The failures group was compared to the successes for differences in mean preinjection RM and VNS scores, age at onset, gender, duration of symptoms prior to injection, length of follow-up, and number of injections. Only the pre-injection VNS scores were significantly different with the successful outcome group having lower scores (8.53 vs. 9.09, $\mathrm{p}=0.04$ ). There were no other significant differences between the groups in any of the variables (Table 4). 
Thirty-eight patients $(38 / 84$ or $45 \%)$ were satisfied with the caudal injections. The 46 patients $(55 \%)$ who were not satisfied with the procedure included 6 patients $(7 \%)$ who stated that the injections helped but they would not repeat the procedure for the same result (Table 5). Patients with successful outcomes were more satisfied $(\mathrm{p}<0.001)$ (Fig. 3).

There were 15 patients with either workman's compensation or no fault insurance. Thirteen of these were in the failures group; one was in the successes group. One was lost to follow-up. There was no significant difference between groups . There were no significant differences between the 13 patients lost to follow-up and the other outcome groups.

\section{DisCussion}

Manchikanti et al (8) evaluated fluoroscopically guided caudal epidural steroid injection as a treatment for low back pain and found it offered $66 \%$ of patients 5.2 weeks of relief after 2 injections. However, Manchikanti et al (8) failed to adequately stratify treated patients into subpopulations, thus possibly diluting the observed actual effect of this treatment in some patients, while inflating the actual effect in others.

Sagar et al (9) studied blind caudal epidural steroid injection in 65 chronic (> 3 months) low back pain patients without neurologic deficit and found that $23 \%$ had a good or fair response and $77 \%$ had a poor response. Breivik et al (10) found that $50 \%$ of patients with chronic low back pain were able to return to work
Table 5. Patient satisfaction

\begin{tabular}{|l|c|c|}
\hline & Frequency & Percent \\
\hline Injections met expectations & 20 & 23.8 \\
\hline Improved less than hoped would undergo again for same result & 18 & 21.4 \\
\hline Injections helped would not undergo again for same result & 6 & 7.1 \\
\hline Same or worse as before injections & 40 & 47.6 \\
\hline Total & 84 & 100.0 \\
\hline
\end{tabular}

after up to three caudal epidural injections were delivered. However, again, the patient population in Breivik et al's (10) study was not adequately defined in terms of pathology and symptomatology.

The present study has been careful to select a subgroup of patients defined by chronic lumbar discogenic pain, to see whether or not fluoroscopic caudal epidural steroid injections would change their long-term outcome. This study found that approximately one in four patients in this population will have a successful long-term outcome following caudal epidural steroid injection at a follow-up of nearly two and a half years.

The success rate of $23 \%$, while matching reported efficacy rates of epidural steroids in chronic low back pain patients recorded in the literature would appear to be within the percentage of patients expected to respond to placebo. This response is reportedly seen in as much as $50 \%$ of patients in various studies and has been shown to preferentially affect patients evaluated with subjective outcome measures such as used in this study (11-13). Even in the absence of treatment, $23 \%$ of patients with chronic low back pain might be expected to improve spontaneously. However, the chronic patient population of this study with a mean duration of symptoms of 21.5 months presumably has out-lived the natural history of possible spontaneous improvement.

The success rate found in this study cannot be compared to the success rate in the Sagar et al (9) or Breivik et al (10) studies because of lack of fluoroscopic guidance and differing patient populations respectively. Nor do the findings in this study contradict the findings in the Manchikanti et al (8) study of 5.2 weeks of relief in $66 \%$ of patients. The length of follow-up in this study ( $28 \pm 15$ months) far exceeds this short time period and the study outcome does not preclude such a period of transient relief.

One could argue that the poor rate of success found in this study may be the result of invalid outcome instruments or criteria for successful outcome set too high. But the validity and reliability of the VNS and Roland-Morris outcome scales is well documented and justifies their use as determinants $(14,15)$. The amount of change in these scales pre and post-in-

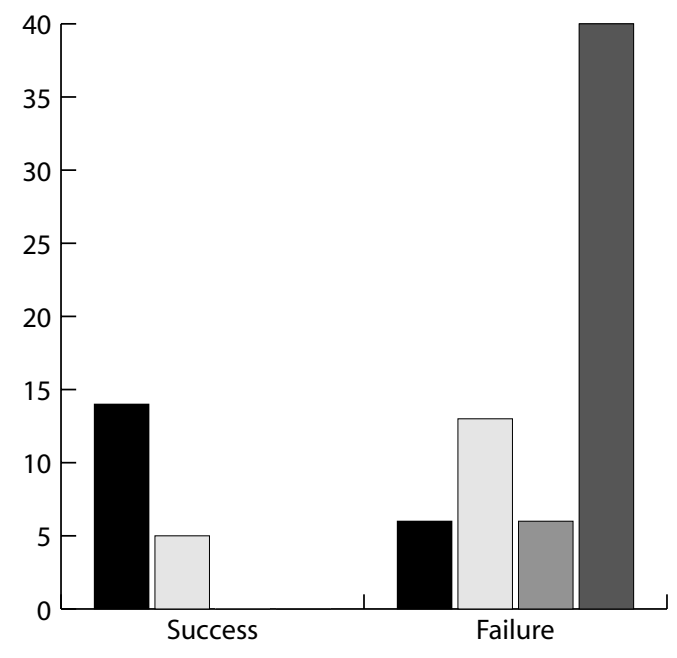

Same or worse as before ES Injection

ES Injection helped, would not repeat

Improved less than hoped, would repeat ES Injection

ES injection met expectations

Fig.3 Patient Satisfaction 
jection deemed necessary for a successful outcome are those commonly in use in other epidural steroid injection studies and, in the case of the Roland-Morris scale, the minimum amount considered clinically significant (15). Yet, how do we explain a patient satisfaction rate of $45 \%$ that is nearly double the success rate? How is it possible for $22 \%$ of patients to claim to be satisfied with a procedure that has failed them? This discrepancy between patient satisfaction and the other outcome scales could be the result of genuine satisfaction with a transient period of relief following injection (as alluded to in the Manchikanti el al's (8) study) that was not sustained at long-term followup. Or it may reflect a bias introduced into the evaluation of those patients interviewed over the phone and asked a direct question regarding satisfaction by an interviewer identifying himself as a member of the medical profession.

The lack of efficacy of caudal epidural steroid injection in this patient population compared with epidural steroid injection in patients with acute radicular pain may be due to the difference in pathoanatomy of each. The most common tissues of origin, by far, for the generation of low back pain has been shown to be the outer layer of the annulus fibrosis and the posterior longitudinal ligament (PLL) (16). The central portions of these tissues are intimately connected and produce centralized back pain when stimulated. The PLL occupies a pivotal anatomic position between the annulus and the dura of the nerve roots. Its rhomboidal shape where it covers the posterior portion of the disc prevents central herniations from contacting the dura. Posterolateral herniations, in contrast, tend to rupture the thinner lateral extensions of the PLL. This causes inflammation where disc material meets the covering of the nerve root with resulting leg pain. Epidural steroids may exert an anti-inflammatory effect providing relief in this situation while having a lesser effect on the mechanical irritation of the annulus and PLL caused by contained central herniations. Fully two thirds of the patients in this study (64/97, $66 \%)$ had contained central or centrolateral herniations as their main diagnosis. It appears that this subset of patients with central disc protrusions may have a different natural history than those patients who have paracentral or foramenal disc herniations.
For a similar reason, it appears that patients with a degenerative disc without a protrusion do not respond as favorably as those with a protrusion (Table 3 ). This may be because the pain generation is from within the disc itself and medication applied to the epidural space would have little effect on this process. The difference in the rate of favorable outcomes between patients with protrusion (14/55 or $25 \%$ ) and those without $(5 / 29$ or $17 \%)$ is suggestive despite failing to attain significance. The smaller numbers in the group without protrusion may affect the power of the study to detect such a difference.

It is also possible that caudal epidural injections are, in fact, effective in patients with a true discogenic source of pain and the high failure rate found in this study is secondary to inaccurate diagnosis. A large number of the non-responders may have an unrecognized non-discogenic source of pain. Epidural steroids would be ineffective, in this case, for failing to reach the target tissues such as the facet joint or sacroiliac joint spaces, etc. Facet joint and sacroiliac joint pain syndromes could not be specifically excluded in this study but it is unlikely that they were present in large numbers. The prevalence of these syndromes in chronic low back pain patients has been estimated to be as low as 9-12\% (17-20). Provocative discography is required for definitive diagnosis of discogenic pain and this was done in $46 \%$ of the failures (30/65) confirming the disc as the source of pain. The remaining 35 patients all had disc pathology on magnetic resonance imaging thought to be relevant to the clinical impression of discogenic pain including 27 with either herniations or annular tears. However, the impression of discogenic pain was not confirmed by discography in these patients.

The caudal route of injection relies on the proximal spread of medication to reach the targeted disc levels. It has been shown that $8 \mathrm{ml}$ of fluid volume injected via the caudal route will reliably reach the L5-S1 and L4-L5 levels (21). Using a minimum of $10 \mathrm{cc}$ of medication volume, it may be assumed that the targeted levels were reached in the $84 \%$ (81/97) of patients with suspected involvement at these levels. Two patients with L3-L4 disc involvement were among the failures.

The limitations of this study are those inherent in the retrospective study in general and include selection bias, lack of blinding, and the lack of a control group with which to compare outcomes and more accurately determine efficacy of steroid injections. The potential bias of telephone interviews that cause patients to be reticent to give negative responses has been mentioned and may have served to improve the predominately negative scores found in this study.

\section{Conclusion}

The efficacy of fluoroscopically guided caudal epidural steroid injections in the management of chronic lumbar discogenic pain when evaluated at long-term follow-up is poor. Only approximately 1 out of 4 patients will achieve significant long-term pain relief and improvement in function. Patient satisfaction, however, exceeds the percentage of patients with successful outcomes. Patients with lower pre-injection VNS scores have greater response to injections. Despite these low success rates, fluoroscopic caudal epidural steroid injection remain a viable option to more invasive treatment options for a significant percentage of this patient population and the offer of at least a single injection should remain part of the treatment algorithm.

\section{Author Affiliation: \\ Daniel Southern, MD}

Hospital for Spinal Surgery,

Department of Physiatry,

535 East $70^{\text {th }} \mathrm{St}$

New York, NY 10021

E-mail: Sagmdsouth@aol.com

\section{Gregory E. Lutz, MD}

Hospital for Spinal Surgery,

Department of Physiatry,

535 East $70^{\text {th }} \mathrm{St}$

New York, NY 10021

E-mail: glutz@hss.edu

\section{Grant Cooper, MD}

Hospital for Spinal Surgery,

Department of Physiatry,

535 East $70^{\text {th }}$ St

New York, NY 10021

E-mail: coopergr@umdnj.edu

\section{Lisha Barre, MD}

Hospital for Spinal Surgery,

Department of Physiatry,

535 East $70^{\text {th }} \mathrm{St}$

New York, NY 10021

E-mail: lbarre@hotmail.com 


\section{REFERENCES}

1. van Tulder MW, Koes BW, Bouter LM et al. Management of Chronic Non-specific Low Back Pain in Primary Care: A descriptive study. Spine 1997;22:76-82.

2. Robechhi A, Capra R. L'idrocortisone (composto F). Prime esperienze cliniche in campo reumatologico. Minverva Med 1952;98:1259-1263.

3. Bogduk N, Brazenor G, Christophides N et al. Epidural steroids in the management of low back pain and sciatica of spinal origin. Report of the working party. Sydney: National Health and Medical Research Council; 1993: 102-106.

4. Bogduk N, Brazenor G, Christophides N et al. Epidural steroids in the management of low back pain and sciatica of spinal origin. Report of the working party. Sydney: National Health and Medical Research Council; 1993:102-106.

5. Singh V, Manchikanti L. Role of caudal epidural injections in the management of chronic low back pain. Pain Physician 2002; 5:133-148.

6. White AH, Derby R, Wynne G. Epidural injections in the diagnosis and treatment of low back pain. Spine 1980; 5:78-86.

7. Lutz GE, Vad VB, Wisneski RJ. Fluoroscopic Transforaminal Lumbar Epidural Steroids: an outcome study. Arch Phys Med Rehabil 1998; 79:1362-1366.
8. Manchikanti L, Pakanati RR, Pampati V. Comparison of three routes of epirduarl steroid injections in low back pain. Pain Digest 1999; 9:277-285.

9. Sagar JV, Sharma R, Sharma S. Epidural steroid injections in non-specific low backache. J Indian Med Assoc 1989; 87:208 209

10. Breivik H, Hesla PE, Molnar I. Treatment of chronic low back pain and sciatica. comparison of caudal epidural injections of bupivacaine and methylprdnisolonwe with bupivacaine followed by saline. In Bonica IJ, Albe-Fessard D (eds). Advances in Pain Research and Therapy. Raven Press, New York, 1976, vol. 1, pp 927-932

11. Beers M, Berkow R: Factors Affecting Drug Response. In Merck Manual of Diagnosis \& Therapy. 17th Ed. Merck + Co, Inc. 1999. Internet Edition by Medical Services USMEDSA, USHH.

12. van der Kuy PH, Lohman JJ. A quantification of the placebo response in migraine prophylaxis. Cephalalgia 2002, May;22: 265-270

13. Hrobrartsson A, Gotzsche PC. Is the placebo powerless? an analysis of clinical trials comparing placebo with no treatment. $N$ Engl J Med 2001; 24:1594-1602.

14. Farrar, JT, Young JP Jr, La Moreaux L et al. Clinical importance of changes in chronic pain intensity measured on an 11-point numerical pain rating scale. Pain 2001;94:
149-158.

15. Roland M, Fairbank J. The Roland-Morris disability questionnaire and the qswestry disability questionnaire. Spine 2000; 25: 3115-3124.

16. Kuslich SD, Ulstrom CL, Michael CJ. The tissue origin of low back pain and sciatica: a report of pain response to tissue stimulation during operation on the lumbar spine using local anesthesia. Orthop Clin N Am 1991; 22: 181-187.

17. Schwarzer AC,Wang S, Bogduk $\mathrm{N}$ et al. Prevalence and clinical features of lumbar zygapophysial joint pain: a study in an Australian population with chronic low back pain. Ann Rheum Diseas 1995;54: 100-106.

18. Schwarzer AC, Aprill CN, Bogduk N. The sacroiliac joint in chronic low back pain. Spine 1995; 20: 31-37.

19. Carette S, Marcoux S, Truchon R et al. A controlled trial of corticosteroid injections into facet joints for chronic low back pain. N Engl J Med 1991; 325: 1002-1007.

20. Jackson RP, Jacobs RR, Montesano PX. Facet joint injection in low-back pain: a prospective statistical study. Spine 1988; 13:966-971.

21. Bryan MB, Lutz C, Lutz GE. Fluoroscopic assessment of epidural contrast spread after caudal injection. Journal of Orthoped Med 2000; 22:3-6. 